\title{
ADEHAUP: Primeras Jornadas de Historia y Patrimonio. Nuevos desafíos
}

La Asociación para el Desarrollo de los Estudios Históricos y Arqueológicos de la Universidad Portucalense es un grupo de estudiantes sin fines lucrativos, nacida por iniciativa de un colectivo integrado por alumnos de la licenciatura en Ciencias Históricas, matriculados en sus diferentes especialidades: Científica, Patrimonial y Educacional. El proyecto nació durante el año lectivo de 1997/98, siendo apoyado desde su primer momento por los profesores del Departamento de Historia. Mientras tanto, se formó una Comisión Científica que terminó por aglutinar también a otros profesores e investigadores de otras universidades portuguesas y extranjeras, institutos y museos, contabilizando miembros de reputadas instituciones como es el caso de Chris Stringer, del Museo de Historia Natural de Londres.

Pese, sin embargo, a hecho de no ser ésta su primera realización, pues habían organizado ya algunas conferencias y visitas de estudio, los miembros directivos y asociados han decidido realizar las Primeiras Jornadas de História e património: novos Desafíos, tras haberse dado cuenta de la expansión de proyecto hacia una perspectiva interdisciplinar donde confluyen la Historia, el Patrimonio y sus respectivas metodologías pedagógicas. Se consideró muy oportuno realizar una reflexión multidisciplinar con la finalidad de complementar las lagunas de los curricula de sus licenciaturas, debatiendo al mismo tiempo los problemas de la Formación- Comunidad Envolvente/ Universidad-Mercado de Trabajo - Salidas Profesionales.

La Comisión Científica y Ejecutiva de las Jornadas definió como objetivos prioritarios:
- Experiencias vinculadas por los trabajos presentados por los conferenciantes invitados. Todos los profesores de la Universidad Portucalense (U.P.) presentaron ponencias dinamizando con su contribución la iniciativa.

- El planteamiento de la Historia como factor conductor al desarrollo económico y social, cuando todos reconocen el estado destartalado que vive esta disciplina en los curricula de la Enseñanza Secundaria en Portugal. El Ministerio de Educación reduce de modo continuado los horarios año tras año, lo que ocasiona altos índices de desempleo en el seno de los recién diplomados.

- Se deseó, igualmente, introducir nuevos temas que siguen, todavía por explorar en los curricula y, en paralelo, la presentación de nuevas perspectivas historiográficas y metodológicas para viejos temas de Historia y Patrimonio.

Las Jornadas tuvieron lugar a lo largo de los días 16,17 y 18 de marzo, terminando con una visita guiada por el arquitecto Manuel Moura del CRUARB (Proyecto Municipal para la Reabilitación del Casco Histórico de Oporto).

El primer día empezó con las comunicaciones dedicadas a la Arqueología presentadas por la mañana, y de las cuales cabe destacar:

- "A Recolha e Preservação dos Achados Arqueológicos (do Campo ao Gabinete) Vítor Hugo Torres (Museo Regional de Arqueologia D. Diogo de Sousa - Braga).

- "A Arte Rupestre do Vale do Côa" - António Martinho Baptista (director del Cen- tro Nacional de Estudios de Arte Rupestre). Hay que señalar que el Valle del Rio Côa es Patrimonio de la Humanidad desde 1998. El comunicante analizó los Museos en proyecto y el estado actual de las investigaciones prehistóricas.

- "A Intervenção Arqueológica no Núcleo Megalítico do Mezio - Arcos de Valdevez" - Nuno Soares.

- "A Musealização dos Povoados da Idade do Ferro : o caso de Cossourado - Paredes de Coura".- Maria de Fátima Silva (U.P.)

- "O Penteado Feminino no Registo Arqueológico" - Maria Antónia Silva.(U.P.).Su autora hizo un estudio etnoarqueológico, desde el mundo protohistórico y romano hasta nuestros días.

Los estudios medievales y Historia Moderna ocuparon la tarde:

- "Estratégias de Afirmação do Poder no Feminino na Alta Idade Média - o Mosteiro de Vairão" - Alcina Manuela Martins (U.P.), primer grado de doctorado en la Universidad Portucalense, obtenido en abril del 99.

- "O Discurso Ideológico da Oligarquia Portuense de Quatrocentos" - Adelaide Costa (Universidad Abierta de Lisboa).

- "O Afecto na Idade Média" - Luís Miguel Duarte (Doctorado de la Facultad de Humanidades de Oporto).

- "Aspectos da Vida Quotidiana das Gentes do Mar nos séculos XVe XVI" - Amândio Barros (Facultad de Humanidades de Oporto) 


\section{Noticias y Comentarios}

- "Conceitos de património e Restauro no Portugal Oitocentista" - Lúcia Rosas (doctorada de la Facultad de Humanidades de Oporto).

La mañana del día siguiente, 17 de marzo, comenzó con ponencias dedicadas a los temas verdaderamente inhabituales:

- "Desafios da tecnologia no Património"Jorge Reis Lima (Inginiero doctorado y director del Departamento de Informatica de la U.P). El comunicante demostró las potencialidades de la Internet como recurso educativo/investigación para los investigadores en Ciencias Humanas.

- "O Legado de Trianon"- Rui Vieira (investigador integrado en un proyecto de la Fundación de la Ciencia y Tecnología). El autor habló de un tema poco común de Historia Contemporánea, puesto que no existe enseñanza de la historia de la Europa Central y del Este en el ámbito del la Enseñanza Superior en Portugal.

- "A História Militar, em Portugal, na Actualidade: balanço de uma Renovação". - Isilda Monteiro (U. P). Su autora defendió la idea de una nueva apertura, alejada del medio castrense tradicional.

- "O Brasil no Discurso Parlamentar" - Fernanda Paula S. Maia (U. P.) doctorada en febrero del año en curso.

En Portugal se celebran este año los 500 años del descubrimiento de Brasil. La tarde versó, una vez más, sobre nuestra historia común con el primer poniente que inauguró la sección de Historia del Arte:

- "Imagens do Brasil dos Primeiros Tempos do século de Quinhentos" - Pedro Dias (doctorado de la Facultadad de Humanidades de Coimbra).

- "A Arte Efémera: uma metodologia"- José Tedim (U. P.), doctorado en marzo pasado.

- "Estudo material das Obras de Arte e Processos Criativos" - Dalila Rodrigues (Insti- tuto Politécnico de Viseu). Esta autora integró, hace muy poco, la comisión de expertos responsables por el análisis de las polémicas cuestiones relacionadas con la identificación de los personajes de los $\mathrm{Pa}$ neles de S. Vicente de Fora, importante pintura cuatrocentista, así como su atribuición al pintor Nuno Gonçalves: defendió la absoluta necesidad de colaboración entre los conservadores-restauradores y los historiadores del Arte.

El día terminó dedicado al Patrimonio y la ponenencia del arquitecto Rui Loza (coordinador del Proyecto Municipal de Rehabilitación Urbana del Casco Histórico) con la cual delineó la evolución de las diferentes tipologías arquitectónicas (popular y erudita) del casco histórico de Oporto y la presentación del proyecto de la Casa da Câmara, asunto que derivó en un encendido debate, que proseguiría el día siguiente. La discusión es consecuencia de las profundas reformas para la celebración de Oporto-Capital Europea de Cultura 2001.

El sábado fue destinado como día del Patrimonio Inmueble y Mueble. Se registraron participaciones de los dos principales órganos oficiales de tutela del patrimonio construido clasificado: Instituto Portugués del Patrimonio Arqueológico y Arquitectónico y la Dirección General de los Edificios y Monumentosa Nacionales.

- "O Mito de Sísifo ou a Recuperação do Património Edificado" - Paulo Pereira (Vice-presidente del IPPAR). Este historiador del arte habló de la ampliación del concepto de patrimonio y de la tarea que significa su conservación. Muy parecida a la del mito de Sísifo, porque jamás termina. La cultura es dinámica, lo que por un lado origina mecanismos de desaparición del patrimonio instituido, por otro crea nuevos fondos patrimoniales.

- "Conservar as Memórias"- Augusto Costa (director regional-Norte da DGMEN). Este arquitecto analizó las metodologías de intervenciones recientes en monumentos bajo la tutela de la DGMEN.
- "A Cor e a Cidade Histórica"- José Aguiar (investigador del Laboratorio Nacional de Ingeniería Civil). Esta fue una excelente ponencia sobre los problemas de la conservación y rehabilitación urbanas, analizando la importancia de los planos de color en las ciudades y del uso y preservación de los materiales tradicionales.

- "Museus, Património e Comunidades" Manuela Pinto da Costa (Profitecla). A través de su trabajo, esta investigadora denunció el riesgo de desaparición de las colecciones de Historia Natural del Museo de Zoología de la Facultad de Ciencias de Oporto, debido a las malas condiciones del edificio. Desafortunadamente, sigue siendo un tipo de patrimonio poco valorado en Portugal.

Las Jornadas terminaron con la comunicación "Questões de Conservação em Torno do Pórtico Principal da Igreja Matriz de Vila do Conde"- Eduarda Moreira da Silva (U.P.). La autora intentó plantear la postura del historiador en un equipo de conservación, intentando, al mismo tiempo, trazar la metolodología de análisis previa a la intervención en cualquier monumento.

La prensa hizo mucho eco de las comunicaciones del día 18.

Eduarda Moreira da Silva (Comissão Científica IExecutiva) A Direcção da ADEHAUP 